Periodica Polytechnica Civil Engineering, 63(2), pp. 647-659, 2019

\title{
Application of Fuzzy Modelling to Predict Construction Projects Cash Flow
}

\author{
Sayed Mohammad Amin Tabei ${ }^{1}$, Morteza Bagherpour ${ }^{2}$, Amin Mahmoudi ${ }^{*}$ \\ ${ }^{1}$ Department of Financial Engineering, \\ University of Economic Science, Tehran, Iran \\ 2 Department of Industrial Engineering, \\ Iran University of Science and Technology, Tehran, Iran \\ ${ }^{3}$ Department of Industrial Engineering, \\ Shiraz Branch, Islamic Azad University, Shiraz, Iran \\ * Corresponding author, e-mail: pmp.mahmoudi@gmail.com
}

Received: 03 November 2018, Accepted: 28 January 2019, Published online: 19 March 2019

\begin{abstract}
Construction project managers are always looking for methods for forecasting future projects and preventing of potential delays in the project. One of the most crucial requirements of construction project managers and financial planners is awareness of project cash flow and financial status. On the other hand, the unique properties of construction projects with uncertainties such as activity duration, the variability of resources, material costs and also ambiguity in the employer's payments are factors that have an effect on the correct prediction of project cash flow. Hence, the project team should examine project cash flow under uncertainty environment. There are many approaches for considering uncertainty such as fuzzy sets, interval theory, rough and grey system. But the most wellknown approach is fuzzy sets which has wide applications in engineering and management. Hence in this paper, we proposed a new method for forecasting project cash flow under fuzzy environment. Finally, the proposed method was applied on an "Engineering, Procurement and Construction" (EPC) project and it is demonstrated that the proposed model has a high performance in the prediction of project cash flow.
\end{abstract}

\section{Keywords}

cash flow, fuzzy sets, predict cash flow, project management, construction projects

\section{Introduction}

Nowadays project management has many applications in different fields such as construction, healthcare and so on. Project is a temporary effort with a specific start and end point [1]. A project can be a unique service or product. In each project there are some constraints including but not limited to time, cost, and scope [2-4].

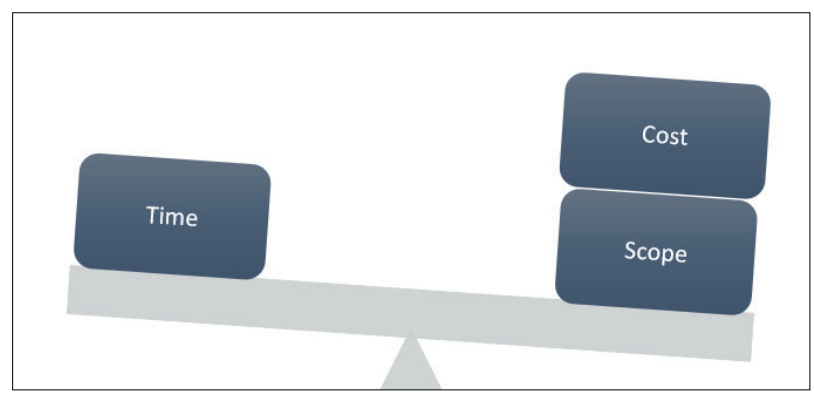

Fig. 1 Balancing between project constraints
The project manager must balance between the mentioned constraints as each project has a different condition and different objectives [5, 6]. Fig. 1 shows triple constraints in the projects and the concept of balancing between them. In each project, one of these constraints can be superior to the other constraints. Project cash flow always helps project managers to balance between constraints and to better manage the cost of projects. Cash flow includes inputs and outputs cash for the project during the life cycle of the project $[7,8]$. Hence the project team should provide project cash flow before starting the project. When a project starts, it is very crucial for stakeholders, especially the contractor, to be already aware of the project cash flow. Incorrect prediction of cash flow may lead to project failure and serious hazard for the organization [9]. Many studies have been conducted to achieve suitable forecasting in project cash 
flow so far. Kenley and Wilson [10] proposed a model for forecasting the project's cash flow according to logic transformation. Their model worked based on historical data and it was suitable for large samples. The standard deviation of the model was between $1 \%$ and $4.6 \%$. Russel [11] stated that more than $60 \%$ of construction contractor failure is due to economic factors.

Lam et al. [12] proposed a multi-objective linear programming and neural network (MOLPNN) for optimization project cash flow. They believed that artificial neural networks are a powerful tool in optimization problems. Their model was applied to 10 projects in Hong Kong. Hwee and Tiong [13] said that with a reliable pre-hand estimation of a project's cash flow, the contractor could be prepared to implement measures that improve the monetary position of comes and create provisions for loans to match with the projected temporal deficit. They presented a model for income prediction and risk analysis for contracting corporations. A computer-based model was introduced in their paper which predicts the cash flow and analyses the effect of risk factors. The five risk factors examined in their paper were: duration, over/under measurement risk, variation risk and material cost variance. Alti [14] studied on sensitivity between investment and cash flow in organizations. He believed that when financing is frictionless and organizations have a high growth rate, sensitivity between investment and cash flow is high. Almeida et al. [15] presented a model for forecasting project cash flow. Their model could consider the relationship between company policies and financial constraints. They examined the performance of their model at many factories and found strong support for the implementation of it. Mavrotas et al. [16] state that an operational program for the information society (OPIS) is one of the important programs of community support framework. They believed that cash flow forecasting is a useful technique for OPIS management. Hence, they developed a model of cash flow forecasting and applied that model to the Operational Programme for the Information Society in Greece. Their model was based on a bottom-up approach starting from the level of a single contract toward the level of the entire programme. They stated that cash flow forecasting plays the role of an early warning system for programs and projects. Park et al. [17] generated a model for cash flow forecasting that used moving weight of cost categories. The base of their model was on the planned value and the actual incurred cost on job site level. Richardson [18] investigated sensitivity between over-investment and free cash flow. Based on this research over-investment is a prevalent issue for US companies. Liu and Wang [19] studied the resource constraint project schedule problem (RCPSP) with considering project cash flow. Their model tried to find maximize profit for projects during the RCPS Problem. Cheng et al. [20] proposed an evolutionary fuzzy hybrid neural network (EFHNN) for better managing project cash flow. They combined neural networks (NN) and high order neural networks (HONN) with each other and presented a new hybrid method. They also used the fuzzy set theory for considering uncertainty in project cash flow. Cui et al. [21] provided a flexible model for management strategies and forecasting project cash flow. The main advantage of their model was integration between cash flow and management strategies. It can support contractors in improving cash flow management. Cash flow forecasting can be a valuable aid to the cash flow manager if it is prepared well. Cheng et al. [22] said that reliable cash flow prediction over the course of construction projects puts the project manager in a better condition to identify problems and develop suitable strategies to mitigate the success of such projects. Jiang et al. [23] proposed a multiple-objective model for cash flow forecasting. They also used 'what-if' analysis for improved decision making by the project manager. A unique property of their model was suitable accuracy for cash flow management when input data is limited. Maravas and Pantouvakis [25] stated that during project implementation, the cash flow is crucial for the assessment of working capital requirement since the difference between project expenditure and payment determines the necessary capital reserves. They proposed a fuzzy cash flow methodology and used fuzzy set theory and fuzzy CPM algorithm that have been introduced by Soltani and Haji [24], to generate fuzzy cash flow methodology. They consider cost and activity duration as factors of uncertainty in the project. They also introduced a fuzzy Gantt chart and S-surface as the two tools in project cash flow forecasting. Hanaoka and Palapus [26] examined the impact of risk on project cash flow using Monte Carlo simulation and game theory. They also used two case studies of the Philippines to illustrate the applicability of the proposed methodology. Bao et al. [27] reexamined research by Riddick and Whited and confirmed that cash flow sensitivity of cash is usually negative when the company faces positive cash flow. In addition, they state that the cash flow sensitivity of cash is positive when the company faces negative cash flow. Larkin [28] believed that intangible assets have a crucial role in financial organization policies. Based on their research, brand perception has a direct impact on cash flow volatility and in a small company, it is extremely powerful. 
Fink and Homberger [29] studied the RCPS Problem with discounted cash flow objectives. They designed a mechanism for RCPSP with discounted cash flow when there are multiple agents in a project.

Alinaitwe et al. [30] studied the reasons for cost overruns and delay in construction projects. They found five major reasons for delay in construction projects as follow:

- Scope creep

- delayed payments

- Weakness in project controlling

- The high cost of capital

- Political insecurity

Alzahrani and Emsley [31] examined success factors of construction projects and its relationship with contractors' attributes. The results showed cash flow forecasting is one of the important factors in construction projects success. Zayed and Liu [32] stated that different factors have an impact on construction project cash flow. They identified impressive factors on project cash flow and presented a model using analytic hierarchy process method. Their model helped contractors during the forecasting of project cash flow. Marzouk and El-Rasas [33] in their research studied on reasons for the delay of construction projects in Egypt. They prepared a list of delay groups in construction projects which included: Owner related, Consultant related, Contractor related, Material related, Labor \& equipment related, Project related and External related. They believed that accuracy in project cash flow forecasting can help project management in controlling delays. Purnus and Bodea [34] proposed a practical model for cash flow in a construction project. Their model was suitable for choosing a reasonable portfolio structure. Based on their analysis the model prevents extra cost in construction projects. Christersson et al. [35] studied energy efficiency at office buildings and their cash flow analysis. They used several methods for evaluating financial performance and presented the advantages of energy efficiency improvement.

Righetto et al. [36] proposed a mixed integer linear programming model using robust optimization for cash flow management in organizations. They conducted a case study in a large company for evaluating the proposed method. Based on the results, robust optimization has good performance in considering project uncertainty. Purnus and Bodea [37] studied financial management in construction projects. Employer and contractor should consider numerous factors in the bed-tender steps. They presented a practical technique for multi-criteria project cash flow analysis. Mohagheghi et al. [38] proposed a model in order to forecast projects cash flow under interval type-2 method. Their model was applied to a construction project and, based on the result, it has high flexibility for considering project uncertainties. Yu et al. [39] developed an algorithm to prepare project cash flow using fuzzy DSM. In their research duration of activities was a fuzzy number and they tried to reduce overlapping of project activates. Ning et al. [40] proposed a method for balancing scheduling and project multi-mode cash flow. They used metaheuristic algorithms such as Tabu search and simulated annealing, and in their research duration of activities has been considered stochastic. Bleyl et al. [41] analyzed the implementation of deep energy retrofit (DER) at office buildings and utilized cash flow in order to calculate cost-benefit analysis. They believed that DER can reduce fossil fuel consumption in the world.

It is not an easy task to find out the relationship between time and cost when the project has many un-measurable activities, activities have different modes or there are more or less independent sub-projects. Without an appropriate net present value (NPV) oriented model and activity variability managing techniques, we cannot handle the issue successfully. It ought to be mentioned that the project cash flow problem theoretically is NP-hard problem with combinatorial explosion in the function of the project size. Therefore, the problem cannot always manage with simple heuristic scheduling methods [42-46]. Many uncertainties influence the correct forecasting of project cash flow such as activity and project duration, cost of resources and materials, and others. In addition to risk factors mentioned above, sometimes due to various reasons such as liquidity shortage in the owner organization, a lesser amount of money is deposited into the contractor's account. There is also a time interval between the time the contractor submits the invoice to the employer and the time the invoice is confirmed and the money is deposited into the contractor's account and this duration usually has some fluctuations which affect project cash flow. The key point that we are going to discuss in this article is that despite all risk factors and uncertainties which were mentioned above, how can a proper model for forecasting project cash flow and costs be designed? In recent years the approach of using fuzzy sets in different fields of science such as decision making, control, modelling and forecasting has increased [47]. One of the most important applications of fuzzy sets is their use in cases with uncertainties. The fuzzy set theory is used to characterize and quantify uncertainty and imprecision in data and functional relationships [48, 49]. In the next section, first we examine preliminary of cash flow forecasting. 


\section{Project cash flow forecasting procedures}

Cash flow is defined as money flow into or out of a project or organization. Cash flow is measured in a certain interval of time. Project cash flow shows the payments (cash out) and receipts (cash in). Therefore, for predicting project cash flow, cash outflow and cash inflow need to be calculated [50]. Project's payments include direct cost of activities and indirect cost of the project. Project receipts usually include payment for approved invoices, advance payment, retention money and others.

In the rest of this paper we will analyze and introduce a model for project cash in and then after determining the amount of cash in, the amount of cash out is determined for different periods. In order to determine the net project cash flow in each period, we will use project cash in and cash out in different periods. We will also use the project contract as an important information source for prediction of the project's cash flow. Typically, in project contract, in addition to project's price, the contracts also have an attachment called invoice procedure that shows in how many intervals the invoice should be sent from contractor to owner and also states the payment method in the project (milestone or progressive). Also, contract deductions of the project such as the deduction for retention money, insurance, taxes are listed in the contract. Fig. 2 illustrates the proposed model. In the rest of this paper, we will show steps for predicting cash inflow and cash outflow.

\section{Nomenclature}

To better understand the proposed method, the variables and parameters of the model are presented in Tablel.

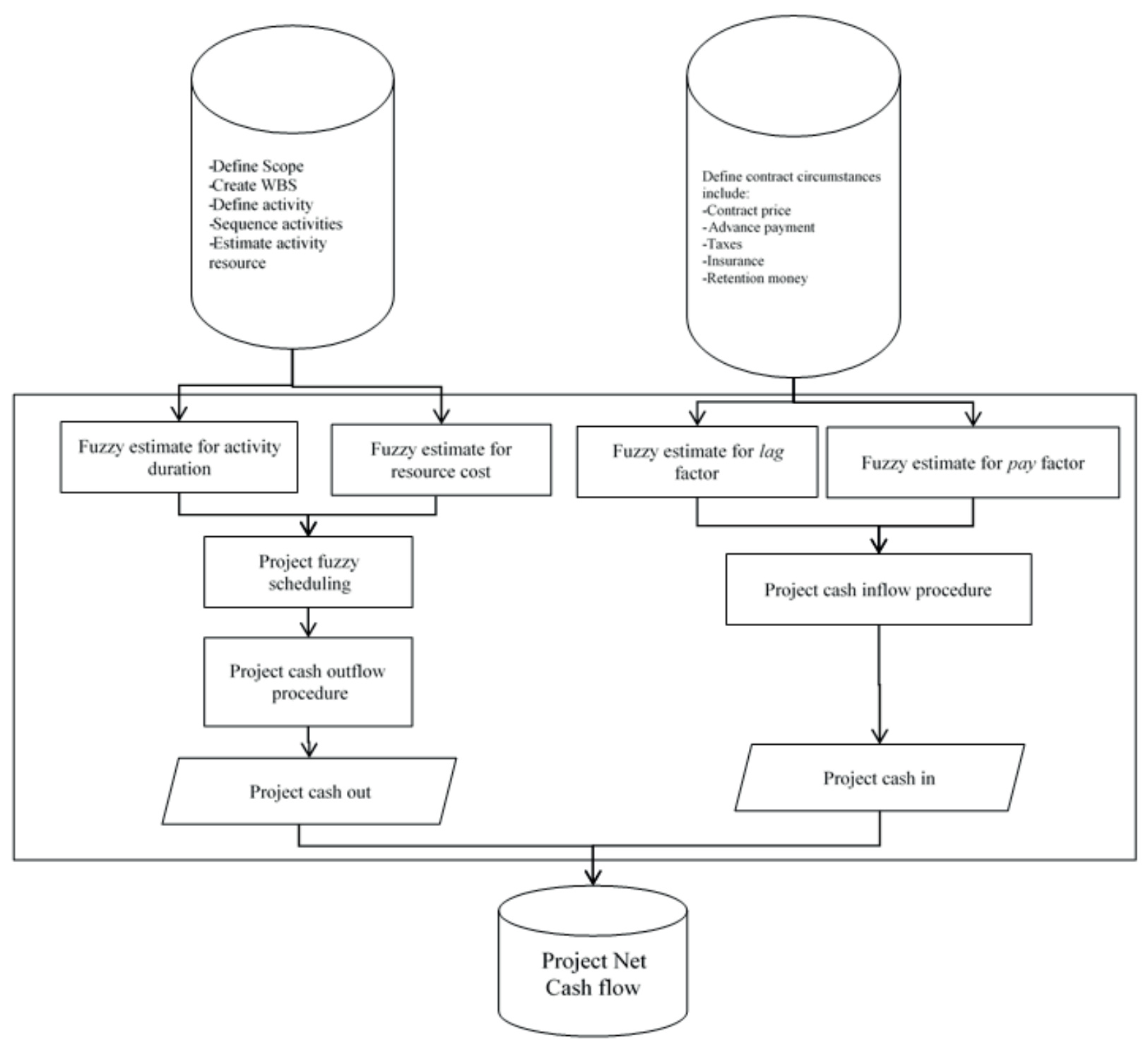

Fig. 2 Project cash flow forecasting fuzzy model 
Table 1 Variables and parameters

\begin{tabular}{|c|c|}
\hline & Variables \& Parameters \\
\hline$C D$ & Cost distribution \\
\hline Inf & Minimum (least) \\
\hline Sup & Maximum (greatest) \\
\hline$C_{a}^{i}$ & Cost of $i^{\text {th }}$ activity with $\alpha-c u t$ equal to $\alpha$ \\
\hline$D_{a}^{i}$ & $\begin{array}{l}\text { Performance periods of } i^{\text {th }} \text { activity with } \alpha-c u t \text { equal } \\
\text { to } \alpha\end{array}$ \\
\hline$D C_{\alpha}(t)$ & $\begin{array}{l}\text { Total direct cost of the project in point } t \text { of project } \\
\text { with } \alpha-\text { cut equal to } \alpha\end{array}$ \\
\hline$T D C$ & Total Direct Cost \\
\hline$C P$ & Contract price \\
\hline$\lambda_{1}$ & $\begin{array}{c}\text { Percentage of benefit that contractor assumes in } \\
\text { tending stage }\end{array}$ \\
\hline$\lambda_{2}$ & $\begin{array}{l}\text { Anticipated percentage of the total indirect cost to } \\
\text { total cost }\end{array}$ \\
\hline $\mathrm{CO}$ & Cash out \\
\hline$T$ & Project duration \\
\hline$I C$ & Indirect cost \\
\hline Pay & $\begin{array}{l}\text { Percentage of the invoice which is confirmed by the } \\
\text { employer }\end{array}$ \\
\hline Lag & $\begin{array}{l}\text { the time interval between sending an invoice and } \\
\text { receiving cash }\end{array}$ \\
\hline$A d v$ & Percentage of advance payment \\
\hline $\operatorname{Re}$ & Percentage of retention money \\
\hline Ins & Percentage of tax and insurance \\
\hline$t_{a d v}$ & $\begin{array}{l}\text { The interval time which the employer has committed } \\
\text { to pay the cash from advance payment to the } \\
\text { contractor }\end{array}$ \\
\hline$t_{r e}$ & $\begin{array}{l}\text { The interval time which the employer has committed } \\
\text { to pay cash from down payment to the contactor }\end{array}$ \\
\hline$t_{\text {ins }}$ & $\begin{array}{l}\text { The interval time after completion of a project that } \\
\text { the contractor may apply for recoupment of insurance } \\
\text { and taxes. }\end{array}$ \\
\hline$K$ & Total number of invoice \\
\hline$i$ & Activity number \\
\hline$m$ & The time interval between sending two invoices \\
\hline$\% \operatorname{Compl}(j)$ & $\begin{array}{l}\text { Project percent complete between } j-1 \text { invoice and } j \\
\text { invoice }\end{array}$ \\
\hline$J$ & Number of invoices \\
\hline$t_{j}$ & The time point of payment \\
\hline$C I$ & Cash in \\
\hline$N C F$ & Net cash flow \\
\hline
\end{tabular}

\section{Project cash outflow forecasting model}

Cash out includes activity cost related to the project such as workshop equipment cost, excavation cost, concrete, cost of materials and human resources. In general, the project's cost is categorized into two classes: direct cost and indirect cost. The direct costs are the costs which are spent on project activities. Direct cost can be allocated to the project network activities. Cost of providing materials, machinery, equipment, and human resources are some examples of the direct costs of the project. Approximately $90 \%$ to $95 \%$ of a project's costs are direct costs [51]. Uncertainty and high volatility in the price of materials and unavailability of accurate data and market risks are the factors which cause uncertainty in the estimation of activity cost and therefore incorrect calculation of project's cash out. Thus, in the proposed model the direct cost of each activity is considered as a fuzzy trapezoidal number. For example, duration and cost of activity $A$ defined in Eqs. (1) and (2).

Duration $(A)=\left(d_{A}^{1}, d_{A}^{2}, d_{A}^{3}, d_{A}^{4},\right)$

$\operatorname{Cost}(A)=\left(C_{A}^{1}, C_{A}^{2}, C_{A}^{3}, C_{A}^{4},\right)$

To determine how much money should be spent in each project period, the cost of each activity must be separated into activity duration. The duration of each activity with a fuzzy number is variable due to different $\boldsymbol{\alpha}-\boldsymbol{c u t}$ and also pessimistic and optimistic scenarios. In the optimistic scenario $\left(\min D_{\alpha}\right)$ the activity begins in the earliest time and is completed within a minimal duration. In the pessimistic scenario $\left(\max D_{\alpha}\right)$ each activity begins at the latest possible time and takes the maximum duration to be completely done. For example, it is assumed that activity has the earliest start time as Eq. (3):

$\widetilde{E S}_{A}=(a, b, c, d)$.

And the earliest finish time is as Eq. (4):

$\widetilde{E F}_{A}=(e, f, g, h)$.

In other words, we will have Eqs. (5) and (6):

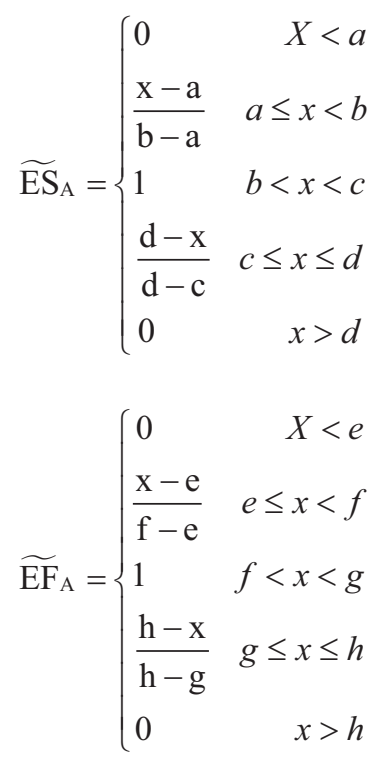


Therefore:

$$
\begin{aligned}
& \min D_{\alpha}=[\operatorname{InfES}, \text { InfES }+ \text { InfES }] \\
& =[\alpha(b-a)+a, \alpha(f-e)+e], \\
& \max D_{\alpha}=\left[\operatorname{Sup} E S_{\alpha}, \operatorname{Sup} E S_{\alpha}+\operatorname{Sup} E S_{\alpha}\right] \\
& =[\alpha(c-d)+d, \alpha(g-h)+h] .
\end{aligned}
$$

To calculate cost per time for each activity we have to divide the cost of the activity to its performance periods. In that case, there are also both pessimistic and optimistic scenarios as Eqs. (9) and (10):

$$
\begin{aligned}
& \operatorname{Min} C D_{\alpha}^{i}(t)=\frac{\operatorname{Inf} C_{\alpha}^{i}(t)}{\operatorname{Inf} D_{\alpha}^{i}(t)}, \\
& \operatorname{Max} C D_{\alpha}^{i}(t)=\frac{\operatorname{Sup} C_{\alpha}^{i}(t)}{\operatorname{Sup} D_{\alpha}^{i}(t)} .
\end{aligned}
$$

Regarding the Eqs. (9) and (10), the total direct cost of the project at time $\underline{t}$ of project is equal to Eqs. (11) and (12):

$$
\begin{aligned}
& \operatorname{MinDC}_{\alpha}(t)=\sum_{i=1}^{n} \operatorname{MinC} D_{\alpha}^{i}(t), \\
& \operatorname{MaxDC}_{\alpha}(t)=\sum_{i=1}^{n} \operatorname{MaxC} D_{\alpha}^{i}(t) .
\end{aligned}
$$

To estimate the total cost at the end of the project and to obtain direct cost curve for both pessimistic and optimistic scenarios, Eqs. (13) and (14) can be used:

$$
\begin{aligned}
& \operatorname{MinTDC}_{\alpha}=\sum_{t=1}^{T} \operatorname{MinDC}_{\alpha}(t), \\
& \operatorname{MaxTDC}_{\alpha}=\sum_{t=1}^{T} \operatorname{MaxDC}_{\alpha}(t) .
\end{aligned}
$$

Indirect costs are the costs which are not directly involved in the project activities. The most important items of indirect cost of projects are project supervision cost, office supplies, wages of the manager of the project and project expert team, office rental, interest penalties resulting from finishing the project work after the deadline, and others. We assume that the amount of total indirect cost of project is as Eq. (15):

$\left(1-\lambda_{1}\right) \times \lambda_{2} \times C P$.

Regarding the above-mentioned cases, for the amount and the time of project's cash out, the steps below should be followed:

First, we state the steps for pessimistic scenarios:

Step 1 - Determine the amount of $\alpha-c u t$

Step 2 - For those activities whose duration has a fuzzy number, determine Duration $_{a}^{\max }$.
Step 3 - According to duration from step 2 and CPM network the project is scheduled and the duration of it is determined which is afterward represented by $T_{a}^{\max }$.

Step 4 - For those activities whose costs have a fuzzy number, determine $C_{a}^{\max }$.

Step 5 - To calculate the cost per time for activities, use Eq. (16) for all activities:

$C D_{\alpha}^{\max }(i)=\frac{C_{\alpha}^{\max }(i)}{D_{\alpha}^{\max }(i)} \quad i=1, \ldots, n$

Step 6 - The total direct cost of the project is calculated as Eq. (17):

$T D C_{\alpha}^{\max }=\sum_{i=1}^{n} \sum_{t=1}^{T} C(i, t)$.

Step 7 - The indirect cost of the project is also divided into project's duration. Its value for each time of the project should be calculated based on Eq. (18):

$I C(t)=\frac{I C}{T}$.

Step 8 - Project cash out is obtained from the addition of direct and indirect costs of activities which are performed in each point of the projects. In order to calculate project cash out Eq. (19) can be used:

$$
C O(t)=\sum_{i=1}^{n} C(i, t)+I C(t) .
$$

Step 9 - The total cash out of the project can be obtained from the addition of the total cash out in the project. Hence Eq. (20) is obtained:

$$
C O_{\alpha}^{\max }=\sum_{t=1}^{T} C O(t) .
$$

\section{Project cash inflow forecasting model}

Due to various financial risks that the employer is faced with, it is likely that a certain percentage of the invoice is not approved by the employer. There could be several reasons including a shortage of funds in the project owner's organization or disagreement between employer and contractor of the work cited. It can be assumed that a percentage of the invoice which is confirmed by the employer contains a fuzzy number as in Eq. (21):

$$
\widetilde{p a y}=\left(\Gamma_{p a y}^{1}, \Gamma_{p a y}^{2}, \Gamma_{p a y}^{3}, \Gamma_{p a y}^{4}\right) \text {. }
$$

In addition to the above-mentioned cases, there is a time lag between the time that the invoice is sent to the employer and the time that the money is deposited to the 
employer's account and this time lag contains uncertainty according to the credit of employer and other conditions. To consider this risk, it can be assumed that this interval of time has a trapezoidal fuzzy number as Eq. (22):

$$
\widetilde{\operatorname{Lag}}=\left(\operatorname{Lag}_{\text {pay }}^{1}, \operatorname{Lag}_{\text {pay }}^{2}, \operatorname{Lag}_{\text {pay }}^{3}, \operatorname{Lag}_{\text {pay }}^{4}\right) \text {. }
$$

Since the completion percentage of the project in different periods of time is a function of activity duration, the activity duration is one of the factors that affects project cash inflow.

Contract terms such as payment method (progressive or milestone), the circumstance of advance payment, the circumstance of retention money, the circumstance of insurance, and tax deduction are other factors that affect project cash inflow in projects.

Generally, it can be assumed that the cash is a function as Eq. (23), with the following parameters:

$$
\begin{aligned}
& \text { CashIN }= \\
& f\left(\text { Duration, adv, re, Ins, } \widetilde{\text { pay }}, \widetilde{\operatorname{Lag}}, t_{\text {adv }}, t_{r e}, t_{\text {Ins }}\right) .
\end{aligned}
$$

To determine the cash in, like cash out, $\alpha-c u t$, payment method and optimistic or pessimistic scenarios should be used to determine the minimum and maximum boundaries for cash in as well as cash out in each point of the project's time.

\subsection{Progressive payment method}

To calculate the amount and point time of cash in, the following procedure is recommended. Notice that these steps should be followed for the pessimistic scenario.

Step 1 - Determine the amount of $\alpha$ for $\alpha-c u t$.

Step 2 - For those activities having fuzzy duration, determine Duration ${ }_{a}^{\max }$

Step 3 - With regard to duration of $2^{\text {nd }}$ step and CPM network, the project is scheduled and its duration is determined by $\left(T_{a}^{\max }\right)$.

Step 4 - Refer to the text of the contract and find the interval when the contractor is supposed to send an invoice to the employer and show this time interval with $m$.

Step 5 - Determine the total number of invoices and calculate it using Eq. (24):

$$
K=\left\{\begin{array}{lll}
\frac{T}{m} & \text { if } & \frac{T}{m}=\text { integer } \\
{\left[\frac{T}{n}\right]+1} & \text { if } & \frac{T}{m} \neq \text { integer }
\end{array} .\right.
$$

Step 6 - The amount of cash inflow from advance payment is equal to Eq. (25):

$$
C I\left(t=t_{\text {start }}+t_{a d v}\right)=a d v \times C P .
$$

Step 7 - The amount of invoices is calculated according to Eq. (26):

$\operatorname{Inv}(J)=(1-r e-a d v-\operatorname{Ins}) \times \% \operatorname{compl}(J) \times C P$

$J=1,2, \ldots, K-1$.

Step 8 - The time point of payment is determined according to Eq. (27):

$t_{j}=m \times J+\operatorname{Lag}_{a} \max \quad J=1,2, \ldots, K$.

Step 9 - Considering the amount obtained from the $8^{\text {th }}$ step and 9th step, Eq. (28) is obtained:

$C I\left(t=t_{j}\right)=\operatorname{Inv}(J) \times P a y_{\min }^{\alpha} \quad J=1,2, \ldots, K-1$.

Step 10 - The amount of the last invoice with respect to deficit or surplus of the payment of the previous invoice is obtained from the Eq. (29):

$$
\begin{aligned}
& \operatorname{Inv}(K)=(1-r e-a d v-\operatorname{Ins}) \times \% \operatorname{compl}(K) \times C P \\
& +\sum_{J=1}^{K-1} \operatorname{Inv}(j)-C a s h \operatorname{In}\left(t=t_{J}\right) .
\end{aligned}
$$

Step 11 - Considering the amount obtained from the $10^{\text {th }}$ step, for the last invoice, Eq. (30) is obtained:

$C I\left(t=t_{k}\right)=\operatorname{Inv}(k)$.

Step 12 - Cash in resulted from the aspects of performance is equal to Eq. (31):

$C I\left(t=T_{a}^{\max }+t_{I n s}\right)=I n s \times C P$.

Step 13 - Cash in from recoupment of funds from insurance and taxes is equal to Eq. (32):

$C I\left(t=T+t_{\text {Ins }}\right)=I n s \times C P$.

Step 14 - The total project cash inflow can be obtained from the multiplication of all the project cash in:

$C I_{\alpha}^{\min }=\sum_{t=1}^{t=T+t_{r e}} C I(t)$.

For an optimistic scenario, the above-mentioned steps are performed with different in steps 2, 8, 9, 14 as follow:

In step 2, Duration ${ }_{\text {min }}^{\alpha}$ is used instead of Duration ${ }_{\text {max }}^{\alpha}$.

In step 8, $\operatorname{Lag}_{\min }^{\alpha}$ is used instead of $\operatorname{Lag}_{\max }^{\alpha}$.

In step 9, $P a y_{\max }^{\alpha}$ is used instead of $P a y_{\text {min }}^{\alpha}$.

In step 14, Cash $\operatorname{In}_{\max }^{\alpha}$ is used instead of Cash $\operatorname{In}_{\text {min }}^{\alpha}$.

\subsection{Milestone payment method}

For calculation of the amount and the point time of cash inflow in the milestone method, the following procedures are suggested. Notice that these steps should be followed for the pessimistic scenario. 
Step 1 - Determine the amount of $\alpha$ for $\alpha$-cut.

Step 2 - For those activities which have fuzzy duration, determine Duration ${ }_{a}^{\max }$

Step 3 - With regard to duration of the $2^{\text {nd }}$ step and CPM network, the project is scheduled and its duration is determined. $\left(T_{a}^{\max }\right)$.

Step 4 - Refer to the text of the contract and identify the milestones on the basis of which the payment is done and define $\mathrm{K}$ as the total number of milestones.

Step 5 - The amount of cash inflow from advance payment is equal to Eq. (34):

$C I\left(t=t_{\text {start }}+t_{\text {adv }}\right)=a d v \times C P$.

Step 6 - The amount of invoices is calculated according to Eq. (35):

$\operatorname{Inv}(J)=(1-r e-a d v-\operatorname{Ins}) \times \phi_{J} \times C P$

$J=1,2, \ldots, K-1$.

Step 7 - The time point when the amount of invoice $j$ is deposited to the contractor's account is calculated as Eq. (36):

$t_{J}=t_{J}^{\text {Milestone }}+\operatorname{Lag}_{\max }^{\alpha} \quad J=1,2, \ldots, K-1$.

Step 8 - Considering the amount obtained from steps 6 and 7, Eq. (37) is obtained:

$C I\left(t=t_{j}\right)=\operatorname{Inv}(J) \times P a y_{\text {min }}^{\alpha} \quad J=1,2, \ldots, K-1$.

Step 9 - The amount of the last invoice with respect to deficit or surplus of the payment of the previous invoice is obtained from Eq. (38):

$$
\begin{aligned}
& \operatorname{Inv}(K)=(1-r e-a d v-\operatorname{Ins}) \times \phi k \times C P+ \\
& \sum_{J=1}^{K-1} \operatorname{Inv}(j)-C \operatorname{ash} \operatorname{In}\left(t=t_{J}\right) .
\end{aligned}
$$

Step 10 - Considering the amount obtained from the $10^{\text {th }}$ step, for the last invoice Eq. (39) should be used.

$C I(t)-t_{K}=\operatorname{Inv}(k)$

Step 11 - Cash in resulted from the aspects of performance is equal to Eq. (40).

$C I\left(t=T_{a}^{\max }+t_{\text {Ins }}\right)=\operatorname{Ins} \times C P$.

Step 12 - Cash in from recoupment of funds from insurance and taxes is equal to Eq. (41).

$C I\left(t=T+t_{I n s}\right)=I n s \times C P$.

Step 13 - The total project cash inflow can be obtained from the multiplication of all the project cash in as Eq. (42):
$C I_{\alpha}^{\min }=\sum_{t=1}^{t=T+t_{r e}} C I(t)$.

For an optimistic scenario the above-mentioned steps are performed differently in steps $2,8,9,14$ as follow:

In step 2, Duration ${ }_{\text {min }}^{\alpha}$ is used instead of Duration ${ }_{\text {max }}^{\alpha}$.

In step $8, \log _{\text {min }}^{\alpha}$ is used instead of $\log _{\text {max }}^{\alpha}$.

In step 9, $P a y_{\text {max }}^{\alpha}$ is used instead of $P a y_{\text {min }}^{\alpha}$

In step $14, C I_{\text {max }}^{\alpha}$ is used instead of $C I_{\text {min }}^{\alpha}$.

\section{Calculation of net project cash flow}

For each level of $\alpha-$ cut and with both pessimistic and optimistic scenarios, we are able to determine cash in and cash out in all intervals of the project.

For pessimistic scenarios we have Eq. (43):

$N C F_{i n f}(t)=C I_{\text {inf }}(t)-C o_{\text {sup }}(t)$.

And for the optimistic scenario, we have Eq. (44):

$N C F_{\text {sup }}(t)=C I_{\text {sup }}(t)-C o_{\text {inf }}(t)$.

For extraction of the project's cash flow S-surface, three dimensions of coordinate axes can be used. $X$ represents project span, $Y$ represents cash flow and $Z$ represents the value of $\alpha-$ cut.

For each $\alpha-$ cut there are two diagrams, one is optimistic diagram and the other is the pessimistic diagram. With the use of this diagram, the status of cash flow can be observed schematically. With the use of net project cash flow, the periods of the project that face a liquidity shortage can be seen and in which intervals of project's time there is a liquidity surplus, so with the use of this information the organization is able to perform financial planning and formulate financial strategies.

\section{Case study}

A contract for an EPC project has been concluded between company A as a contractor and company B as an employer. The contract price is $\$ 300$ million. The method of payment in this contract is based on a progress percentage method. The advance payment rate is equal to $10 \%$ of the total project's price and the employer should pay after two weeks after the project's effective date. In the contract of the project, $5 \%$ for insurance deduction and $5 \%$ for tax deduction have been considered and this amount is subtracted from the invoice after finishing the project and presenting legal documentation and the contractor can receive $10 \%$ of the subtracted sum at the end of the project. The retention money is also equal to $20 \%$ of the contract price 
and that is payable six months after finishing the project if all the technical specifications have been followed. It is also mentioned in the project contract that the contractor can issue invoices at two-month intervals. Considering the prediction done by the unit of accounting and cost control of the contractor's company, it is predicted that the indirect cost of the project is $\$ 10$ million. Given the existing uncertainties such as equipment of contractor's team members, it is expected that the deviation from the mentioned start date would have the fuzzy trapezoidal number of $(0,5,15$, and 20) days. Also, according to the historical data from the past projects, planning and cost control team predicts that a percentage of each invoice that is confirmed by the contractor has a fuzzy trapezoidal number as Eq. (45):

$$
\widetilde{P a y}=(0.9,0.91,1,1.01) \text {. }
$$

Also, the time interval in which the invoice is sent to the employer and the cash is paid to the contractor of the project has trapezoidal fuzzy number based on the months:

$$
\widetilde{\operatorname{Lag}}=(0.1,0.2,0.5,0.6) \text {. }
$$

According to the given information and the notations which have been used, we have the following equations:

$$
a d v=0.1 \text {, }
$$

$r e=0.2$,

$t_{a d v}=0.5$,
Ins $=0.1$

$t_{\text {Ins }}=1$,

$t_{r e}=6$.

The project is solved with the use of ten $\alpha$-cuts and both optimistic and pessimistic scenarios and for each $\alpha$ - cuts lower and upper limits have been delineated for the project's cash flow. Fig. 3 is a diagram of project's cash outflow. This diagram has three axes. The $X$ axis shows $\alpha$ - cuts, the $Y$ axis shows time span of project and the $Z$ axis shows cumulative cash outflow.

After testing the proposed model in running project it was observed that in $81 \%$ of cases, the project cash in was between the upper and lower limit that was predicted by the model.

Comparing the forecast and actual cash inflow, in $84 \%$ of the cases, the actual value of the project's cash inflow is between the predicted lower and upper limits. Project cash inflow is shown in Fig. 4.

Finally, in $76 \%$ of cases the actual obtained value for net project's cash flow is between the predicted lower and upper limits. Fig. 5 shows the cumulative net project cash flow.

By using Figs. 3, 4 and 5, a project finance manager can better understand the liquidity situation in the life span of the project. As can be seen in the figures, it is predicted that there would be a cash deficit at some period of project span;

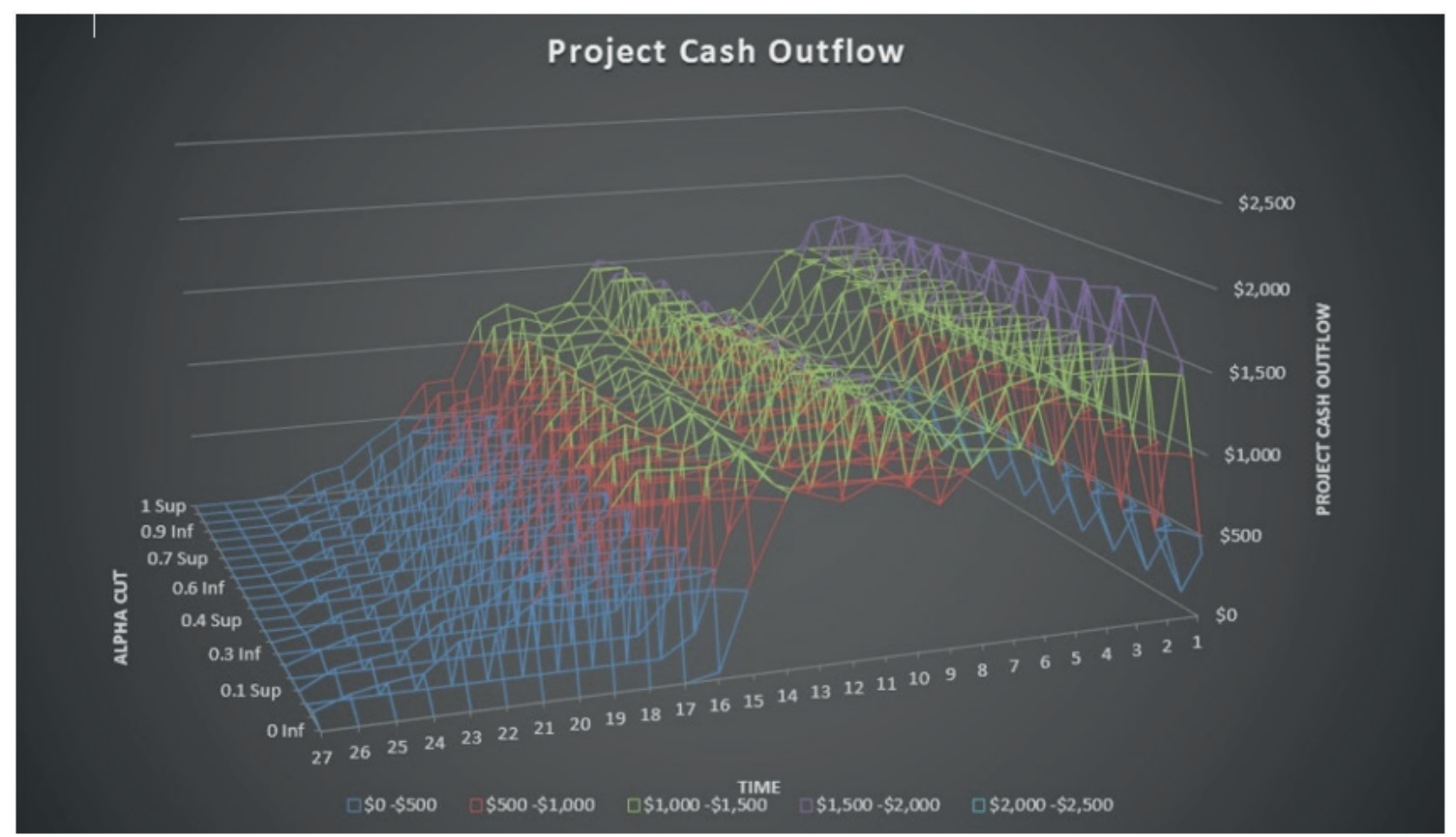

Fig. 3 S-Surface of project fuzzy cash outflow 


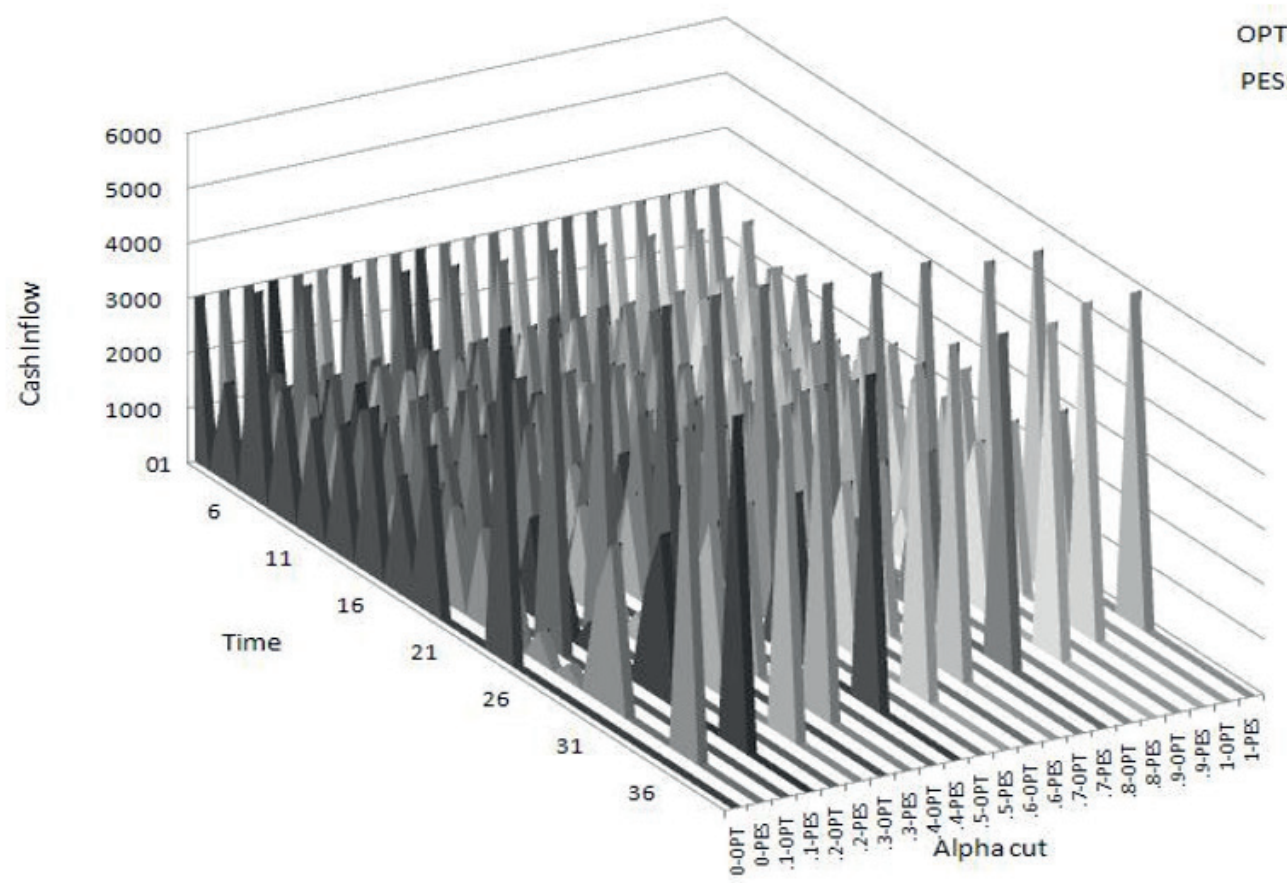

OPT: optimistic

PES: Pessimistic

Fig. 4 Project fuzzy cash flow

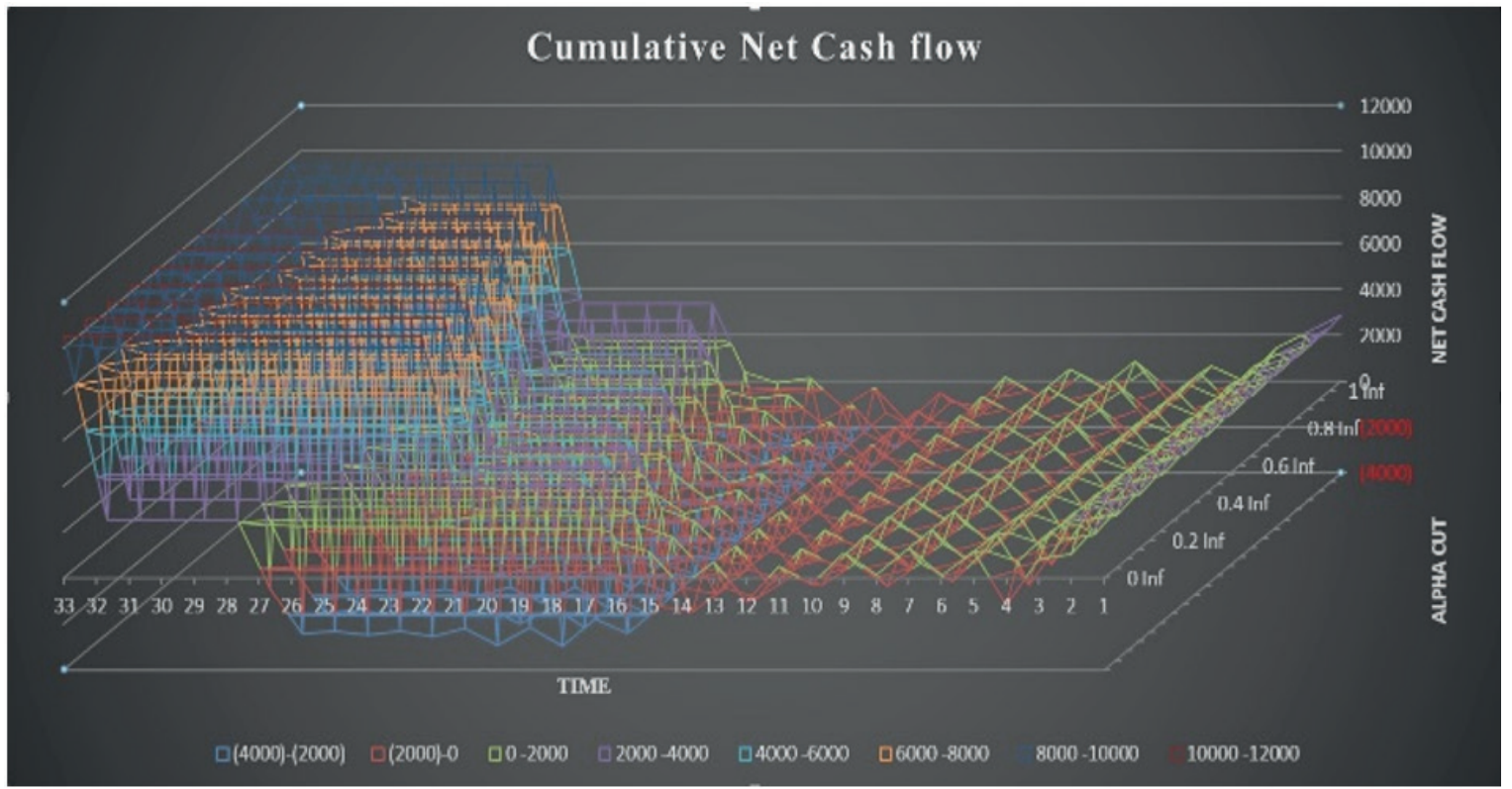

Fig. 5 Fuzzy cumulative net cash flow diagram

such as 6,12, 14-time units of the project. With a pessimistic scenario, we also have a deficit on the periods between 15 and 26. To solve this problem, the project financial manager should provide funding for project from a funding agency or use project financing method. Based on the results key benefits of the proposed method are as follows:

- Considering uncertainties includes uncertainty of start date, uncertainty of activity duration, uncertainty of resource and material cost, uncertainty of amount of money from the invoice that the project's owner has been approved and uncertainty about lead time for money that contractor will receive.

- Two different methods proposed for cash inflow forecasting depending on progressive payment method or milestone payment method.

- Early warning in money deficit situations.

- The output of the model can be used as valid input for applying fuzzy earned value method. 


\section{Conclusions}

The aim of the proposed model is to develop project cash procedures and define upper and lower bond for cash inflows and cash outflows. It also considers five main risk factors that are a concern for contractors and influences on correct project cash flow forecasting. These factors are the uncertainty of project start date; uncertainty of activity duration; uncertainty of resource and material cost; uncertainty about the amount of money from the invoice that the project's owner has approved; and uncertainty about lead time for money that contractor will receive. Two different methods are proposed for cash inflow forecasting depending on progressive payment method or milestone

\section{References}

[1] Mahmoudi, A., Feylizadeh, M. R. "A mathematical model for crashing projects by considering time, cost, quality and risk", Journal of Project Management, 2(1), pp. 27-36, 2017.

https://doi.org/10.5267/j.jpm.2017.5.002

[2] Project Management Institute "A guide to the project management body of knowledge - PMBOK® Guide", 5th ed., Project Management Institute, Newtown Square, Pennsylvania, United States, 2013.

[3] Caldas, C., Gupta, A. "Critical factors impacting the performance of mega-projects", Engineering, Construction and Architectural Management, 24(6), pp. 920-934, 2017, https://doi.org/10.1108/ECAM-05-2016-0117

[4] Khanzadi, M., Attar, A. M., Bagherpour, M. "Finding Optimum Resource Allocation to Optimizing Construction Project Time/Cost through Combination of Artificial Agents CPM and GA", Periodica Polytechnica Civil Engineering, 60(2), pp. 169-180, 2016. https://doi.org/10.3311/PPci.7883

[5] Mahmoudi, A., Feylizadeh, M. R. "A grey mathematical model for crashing of projects by considering time, cost, quality, risk and law of diminishing returns", Grey Systems: Theory and Application, 8(3), pp. 272-294, 2018.

https://doi.org/10.1108/GS-12-2017-0042

[6] Feylizadeh, M. R., Mahmoudi, A., Bagherpour, M., Li, D-F. "Project crashing using a fuzzy multi-objective model considering time, cost, quality and risk under fast tracking technique: A case study", Journal of Intelligent \& Fuzzy Systems, 35(3), pp. 3615-3631, 2018. https://doi.org/10.3233/JIFS-18171

[7] Project Management Institute "Practice standard for earned value management", 2nd ed., Project Management Institute, Newtown Square, Pennsylvania, United States, 2011.

[8] Motawa, I., Kaka, A. "Modelling payment mechanisms for supply chain in construction", Engineering, Construction and Architectural Management, 16(4), pp. 325-336, 2009. https://doi.org/10.1108/09699980910970824

[9] Beran, V., Dlask, P. "Nonlinear optimisation and rational cash flow", Engineering, Construction and Architectural Management, 14(3), pp. 277-292, 2007.

https://doi.org/10.1108/09699980710744917 payment method. Finally, a step by step procedure is supposed that has been easily done by project managers and financial planners. The proposed procedure can be implemented by common software such as Microsoft Excel and Project managers and Microsoft Project. Financial planners can use the model as a proper tool for early warning in money deficit situations. The output of the model can be used as valid input for applying fuzzy earned value method. In future study different uncertainty approaches can be used and compared with the current study. Also, other risks can be considered that are involved with project cash flow.

[10] Kenley, R., Wilson, O. D. "A construction project cash flow model an idiographic approach", Construction Management and Economics, 4(3), pp. 213-232, 1986. https://doi.org/10.1080/01446198600000017

[11] Russell, J. S. "Contractor Failure: Analysis", Journal of Performance of Constructed Facilities, 5(3), pp. 163-180, 1991. https://doi.org/10.1061/(ASCE)0887-3828(1991)5:3(163)

[12] Lam, K. C., Hu, T., Cheung, S. O., Yuen, R. K. K., Deng, Z. M. "Multi-project cash flow optimization: non-inferior solution through neuro-multiobjective algorithm", Engineering, Construction and Architectural Management, 8(2), pp. 130-144, 2001. https://doi.org/10.1108/eb021176

[13] Hwee, N. G., Tiong, R. L. K. "Model on cash flow forecasting and risk analysis for contracting firms", International Journal of Project Management, 20(5), pp. 351-363, 2002. https://doi.org/10.1016/S0263-7863(01)00037-0

[14] Alti, A. "How Sensitive Is Investment to Cash Flow When Financing Is Frictionless?", The Journal of Finance, 58(2), pp. 707-722, 2003. https://doi.org/10.1111/1540-6261.00542

[15] Almeida, H., Campello, M., Weisbach, M. S. "The Cash Flow Sensitivity of Cash", The Journal of Finance, 59(4), pp. 1777-1804, 2004. https://doi.org/10.1111/j.1540-6261.2004.00679.x

[16] Mavrotas, G., Caloghirou, Y., Koune, J. "A model on cash flow forecasting and early warning for multi-project programmes: application to the Operational Programme for the Information Society in Greece", International Journal of Project Management, 23(2), pp. 121-133, 2005. https://doi.org/10.1016/J.IJPROMAN.2004.07.009

[17] Park, H. K., Han, S. H., Russell, J. S. "Cash Flow Forecasting Model for General Contractors Using Moving Weights of Cost Categories", Journal of Management in Engineering, 21(4), pp. 164-172, 2005. https://doi.org/10.1061/(ASCE)0742-597X(2005)21:4(164)

[18] Richardson, S. "Over-investment of free cash flow", Review of Accounting Studies, 11(2-3), pp. 159-189, 2006. https://doi.org/10.1007/s11142-006-9012-1

[19] Liu, S.-S., Wang, C-J. "Resource-constrained construction project scheduling model for profit maximization considering cash flow", Automation in Construction, 17(8), pp. 966-974, 2008. https://doi.org/10.1016/j.autcon.2008.04.006 
[20] Cheng, M.-Y., Tsai, H-C., Sudjono, E. "Evolutionary fuzzy hybrid neural network for project cash flow control", Engineering Applications of Artificial Intelligence, 23(4), pp. 604-613, 2010. https://doi.org/10.1016/J.ENGAPPAI.2009.10.003

[21] Cui, Q., Hastak, M., Halpin, D. "Systems analysis of project cash flow management strategies", Construction Management and Economics, 28(4), pp. 361-376, 2010. https://doi.org/10.1080/01446191003702484

[22] Cheng, M.-Y., Roy, A. F. V. "Evolutionary fuzzy decision model for cash flow prediction using time-dependent support vector machines", International Journal of Project Management, 29(1), pp. 56-65, 2011.

https://doi.org/10.1016/J.IJPROMAN.2010.01.004

[23] Jiang, A., Issa, R. R. A., Malek, M. "Construction Project Cash Flow Planning Using the Pareto Optimality Efficiency Network Model", Journal of Civil Engineering and Management, 17(4), pp. 510-519, 2011. https://doi.org/10.3846/13923730.2011.604537

[24] Soltani, A., Haji, R. "A Project Scheduling Method Based on Fuzzy Theory", Journal of Industrial and Systems Engineering, 1(1), pp. 70-80, 2007.

[25] Maravas, A., Pantouvakis, J.-P. "Project cash flow analysis in the presence of uncertainty in activity duration and cost", International Journal of Project Management, 30(3), pp. 374-384, 2012. https://doi.org/10.1016/J.IJPROMAN.2011.08.005

[26] Hanaoka, S., Palapus, H. P. "Reasonable concession period for build-operate-transfer road projects in the Philippines", International Journal of Project Management, 30(8), pp. 938-949, 2012. https://doi.org/10.1016/J.IJPROMAN.2012.02.001

[27] Bao, D., Chan, K. C., Zhang, W. "Asymmetric cash flow sensitivity of cash holdings", Journal of Corporate Finance, 18(4), pp. 690700, 2012.

https://doi.org/10.1016/J.JCORPFIN.2012.05.003

[28] Larkin, Y. "Brand perception, cash flow stability, and financial policy", Journal of Financial Economics, 110(1), pp. 232-253, 2013. https://doi.org/10.1016/J.JFINECO.2013.05.002

[29] Fink, A., Homberger, J. "An ant-based coordination mechanism for resource-constrained project scheduling with multiple agents and cash flow objectives", Flexible Services and Manufacturing Journal, 25(1-2), pp. 94-121, 2013. https://doi.org/10.1007/s10696-012-9136-5

[30] Alinaitwe, H., Apolot, R., Tindiwensi, D. "Investigation into the Causes of Delay and Cost Overrun in Uganda's Public Sector Construction Projects", Journal of Construction in Developing Countries, 18(2), pp. 33-47, 2013. [online] Available at: http://web. usm.my/jcdc/vol18_2_2013/JCDC\%2018(2)\%202013-Art.\%20 3\%20(33-47).pdf [Accessed: 11.03.2019]

[31] Alzahrani, J. I., Emsley, M. W. "The impact of contractors' attributes on construction project success: A post construction evaluation", International Journal of Project Management, 31(2), pp. 313-322. 2013. https://doi.org/10.1016/J.IJPROMAN.2012.06.006

[32] Zayed, T., Liu, Y. "Cash flow modeling for construction projects", Engineering, Construction and Architectural Management, 21(2), pp. 170-189, 2014.

https://doi.org/10.1108/ECAM-08-2012-0082
[33] Marzouk, M. M., El-Rasas, T. I. "Analyzing delay causes in Egyptian construction projects", Journal of Advanced Research, 5(1), pp. 49-55, 2014. https://doi.org/10.1016/J.JARE.2012.11.005

[34] Purnus, A., Bodea, C.-N. "Financial Management of the Construction Projects: A Proposed Cash Flow Analysis Model at Project Portfolio Level", Organization, Technology \& Management in Construction: An International Journal, 7(1), pp. 1217-1227, 2015. https://doi.org/10.5592/otmcj.2015.1.6

[35] Christersson, M., Vimpari, J., Junnila, S. "Assessment of financial potential of real estate energy efficiency investments - A discounted cash flow approach", Sustainable Cities and Society,18, pp. 66-73, 2015.

https://doi.org/10.1016/J.SCS.2015.06.002

[36] Righetto, G. M., Morabito, R., Alem, D. "A robust optimization approach for cash flow management in stationery companies", Computers \& Industrial Engineering, 99, pp. 137-152, 2016. https://doi.org/10.1016/J.CIE.2016.07.010

[37] Purnus, A., Bodea, C.-N. "Multi-criteria Cash Flow Analysis in Construction Projects", Procedia Engineering, 164, pp. 98-105, 2016. https://doi.org/10.1016/J.PROENG.2016.11.597

[38] Mohagheghi, V., Mousavi, S. M., Vahdani, B. "Analyzing project cash flow by a new interval type-2 fuzzy model with an application to construction industry", Neural Computing and Applications, 28(11), pp. 3393-3411, 2017. https://doi.org/10.1007/s00521-016-2235-6

[39] Yu, M.-C., Yeh, H.-C., Dang, V.-L. "Measuring cash flow and overdraft for fuzzy project networks with overlapping activities", Journal of Civil Engineering and Management, 23(4), pp. 487-498, 2017. https://doi.org/10.3846/13923730.2016.1210215

[40] Ning, M., He, Z., Jia, T., Wang, N. "Metaheuristics for multi-mode cash flow balanced project scheduling with stochastic duration of activities", Automation in Construction, 81, pp. 224-233, 2017. https://doi.org/10.1016/J.AUTCON.2017.06.011

[41] Bleyl, J. W., Bareit, M., Casas, M. A., Chatterjee, S., Coolen, J. et al. "Office building deep energy retrofit: life cycle cost benefit analyses using cash flow analysis and multiple benefits on project level", Energy Efficiency, 12(1), pp. 261-279, 2018. https://doi.org/10.1007/s12053-018-9707-8

[42] Csébfalvi, A., Láng, B. "An improved hybrid method for the resource-constrained project scheduling problem with discounted cash flows", Pollack Periodica, 7(1), pp. 135-146, 2012. https://doi.org/10.1556/Pollack.7.2012.1.13

[43] Csébfalvi, A. "A Unified Model For Resource-Constrained Project Scheduling Problem With Uncertain Activity Durations", International Journal of Optimization in Civil Engineering, 2(3), pp. 341-355, 2012. [online] Available at: http:/ijoce.iust.ac.ir/article-195-en.html [Accessed: 12.03.2019]

[44] Csébfalvi A., Szendrői, E. "An Improved Hybrid Method for the Multi-Mode Resource-Constrained Project Scheduling Problem", In: Proceedings of the Eighth International Conference on Engineering Computational Technology, Dubrovnik, Croatia, 2012, pp. 1-13. https://doi.org/10.4203/ccp.100.50 
[45] Danka, S., Csébfalvi, A. "A Hybrid Metaheuristic for Project Scheduling Problems with Fuzzy Activity Durations to support the Ös-Dráva Water Management Programme", In: Proceedings of the Eighth International Conference on Engineering Computational Technology, Dubrovnik, Croatia, 2012, pp. 1-20. https://doi.org/10.4203/ccp.100.65

[46] Csébfalvi, A., Csébfalvi, G. "Hammock Activities in Project Scheduling", Presented at Sixteenth Annual Conference of POMS, Chicago, Illinois, USA, 2005. Available at https://www.researchgate.net/publication/288827881_Hammock_Activities_in Project_Scheduling [Accessed: 12.03.2019]

[47] Mahmoudi, A., Feylizadeh, M. R., Darvishi, D., Liu, S. "Grey-Fuzzy solution for multi-objective linear programming with interval coefficients", Grey Systems: Theory and Application, 8(3), pp. 312-327, 2018.

https://doi.org/10.1108/GS-01-2018-0007
[48] Zadeh, L. A. "The concept of a linguistic variable and its application to approximate reasoning-III," Information Sciences, 9(1), pp. 43-80, 1975.

https://doi.org/10.1016/0020-0255(75)90017-1

[49] Bonnal, P., Gourc, D., Lacoste, G. "Where Do We Stand with Fuzzy Project Scheduling?", Journal of Construction Engineering and Management, 130(1), pp. 114-123, 2004.

https://doi.org/10.1061/(ASCE)0733-9364(2004)130:1(114)

[50] Sharifi, M. M., Bagherpour, M. "Optimizing Cash-Flow-at-Risk in Construction Projects: A Cost Reduction Approach", Periodica Polytechnica Civil Engineering, 60(3), pp. 337-344, 2016. https://doi.org/10.3311/PPci.7884

[51] Bermudez-Tamayo, C., Besançon, S., Johri, M., Assa, S., Brown, J. B., Ramaiya, K. "Direct and indirect costs of diabetes mellitus in Mali: A case-control study", PloSONE, 12(5), 2017.

https://doi.org/10.1371/journal.pone.0176128 